\title{
Characterization of Responsive Plasters for Passive Moisture and Temperature Control
}

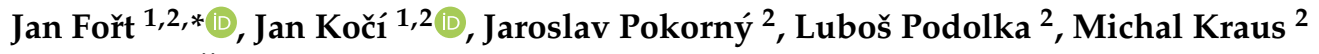 \\ and Robert Černý ${ }^{1}$ \\ 1 Department of Materials Engineering and Chemistry, Faculty of Civil Engineering, \\ Czech Technical University in Prague, Thákurova 7, 16629 Prague, Czech Republic; \\ jan.koci@fsv.cvut.cz (J.K.); cerny@fsv.cvut.cz (R.Č.) \\ 2 Department of Civil Engineering, Institute of Technology and Business in České Budějovice, \\ Okružní 517/10, 37001 České Budějovice, Czech Republic; pokorny@mail.vstecb.cz (J.P.); \\ podolka@mail.vstecb.cz (L.P.); krausm@mail.vstecb.cz (M.K.) \\ * Correspondence: jan.fort@fsv.cvut.cz; Tel.: +420-775-013-150
}

Received: 18 November 2020; Accepted: 17 December 2020; Published: 20 December 2020

check for updates

\begin{abstract}
Ambient comfort maintenance accompanied by excessive energy consumption is hugely criticized concerning the limited sustainability of the building sector in the long-term. In this sense, the energy reduction strategies based on the employment of passive air-control techniques are viewed as a prospective solution for improved energy performance. In order to contribute to this significant issue, this paper is aimed at the design and material characterization of novel plaster with an improved thermal and humidity control performance. For this purpose, a form-stable diatomite/dodecanol-based phase change material together with superabsorbent polymer are used as admixtures for the passive moderation of indoor air quality by newly designed modified plasters. The experimental assessment of the functional properties by means of mechanical strength, thermal conductivity, and hygric properties is performed. Considering the goal of the paper, particular attention is paid to the characterization of water vapor storage and moisture buffering according to the Nordtest method. Differential scanning calorimetry is employed for the description of phase change intervals as well as the specific enthalpy of phase change. The obtained results point to significant improvements in the hygroscopic performance and increased thermal energy storage that can be used for passive moderation of the indoor temperature and reduction of the relative humidity swings.
\end{abstract}

Keywords: phase change material; diatomite; superabsorbent polymer; humidity control; indoor air

\section{Introduction}

The energy consumption of the building sector still represents a substantial issue considering the population boom and increased thermal comfort requirements [1]. The utilization of heat, ventilation, and air-conditioning (HVAC) devices goes with noticeable energy consumption, and the building sector contributes almost $40 \%$ of the total energy consumption. In other words, substantial improvements need to be achieve in roder to reach the nearly zero-energy building targets and the overall mitigation of the negative environmental impact of the building sector [2].

The energy efficiency of buildings depends substantially on the hygrothermal parameters of materials applied in building envelopes [3]. In this sense, a detailed characterization of heat and moisture transport, including the storage parameters of building materials, plays a crucial role within the optimization and design of energy-efficient building envelopes [4-6]. The potential improvements in the ambient thermal comfort were studied in detail, predominantly via the optimization of the building envelope layers, including the application of advanced insulation materials such as vacuum-insulation 
panels and aerogels, or based on passive energy storage systems. The achieved results refer to the substantial benefits related to potential energy savings thanks to the decreased temperature peaks, caused by phase change materials (PCMs) that act as a medium with the ability to absorb or release thermal energy according to ambient temperature [7-9]. In particular, the application of PCMs in climate zones with noticeable diurnal temperature swings may be viewed as an advisable strategy. As reported by Refs. [10-12], distinct energy savings can be obtained with the help of the incorporation of PCMs into building elements such as walls, floors, and roofs. On the other hand, the utilization of PCMs is accompanied by several critical issues, including the limited mechanical performance, leakage of PCMs, subcooling phenomena, and the limited range of the phase change $[13,14]$. The type and applied dosage of PCM in building composites have been questioned by several researchers, since the equilibrium between satisfactory mechanical performance and thermal storage capacity needs to be described [15-18]. Further improvements related to the mentioned PCM drawbacks have been subjected to comprehensive research, and a detailed understanding of the outdoor climatic conditions and indoor requirements can be found in several studies and review papers [19-21].

Besides the heat transfer, the moisture transport and storage properties of porous building materials have a significant effect on energy efficiency as well. This phenomenon was studied in detail for typical building materials such as bricks, aerated concrete, plasters, and insulation materials in particular to provide insight into the interaction between water content and thermal performance [22-24]. As revealed, the effect of moisture content could result in a substantial deterioration of thermal insulation capability $[25,26]$. In other words, the moisture-related issues require significant attention, and the neglect of the correlation between moisture and heat transfer may result in very unpleasant consequences [27-29]. Namely, undesirable levels of indoor moisture may cause considerable health issues, such as asthma, allergies, skin or eye irritation, etc. The aforementioned issues further increase the importance of the complex assessment and control of indoor air quality, taking into account both the thermal and moisture buffering of building materials in order to prevent the risk of Sick Building Syndrome [30] or other unpleasant consequences. The moisture buffering performance is usually described by the help of the moisture buffer value (MBV), which refers to the capability of the applied finishing building materials to respond to moisture loads, thus balancing the excessive or too-low levels of relative humidity [31,32]. While the common building materials usually exhibit a limited moisture buffer performance, modifications based on various porogene or highly hygroscopic lightweight aggregates have been found useful [33]. Notwithstanding, the results obtained by Buratti et al. [34] or Park et al. [35] refer to only minor improvements, and do not lead to a satisfactory or complex solution in terms of indoor comfort. Nevertheless, thanks to the rapid development of new materials, superabsorbent polymers (SAP) in particular have been studied as potential candidates for the modification of the hygric properties of building materials with particular success. SAPs, primarily used as an internal curing agent in concrete mixture design, may find beneficial application also in finishing layers due to their remarkable water absorption capability. The revealed findings in the work of Senff et al. [36] point to substantial improvements in moisture buffering and consequent relative humidity control. However, the incorporation of SAPs into load-bearing structures struggles with the adverse effects on functional parameters, thus only a limited amount of SAP admixture could be used. On the other hand, the precise material design and utilization in non-bearing building elements allows a significant extension of the functional properties by means of the improved water absorption and retention of SAPs.

Taking into account the increased attention paid to ambient air quality maintenance with emphasis on low-energy solutions, advanced materials based on the application of modern admixtures may provide an adequate and sustainable solution. As revealed above, recently-developed materials can be utilized in building materials in order to preserve stability and the desired indoor conditions in terms of temperature and humidity preservation. Since reliable and applicable results from the advanced building materials are required for further research, including computational modeling, this paper 
contemplates the utilization of concurrent SAP and PCM application in interior cement-lime plasters as a complex solution for a passive indoor air quality moderation system.

\section{Materials and Methods}

\subsection{Studied Materials}

As a base material for PCM and SAP incorporation, a commercially available cement-lime plaster Weber MV1 composed of cement, lime, and sand in a 1:1:5 ratio was used. While the effect of individual admixtures was described in previous publications, the mutual interaction of both SAP and PCM admixtures has not been elaborated yet [15,37-39]. In this sense, the previously developed form-stable PCM based on a diatomite/dodecanol composite with pozzolanic activity was used as a latent heat storage medium [39]. The phase change intervals of the used PCM are shown in Figure 1. As one can see, the phase change interval ranged from 22 to $25^{\circ} \mathrm{C}$ during heating, respectively, and from 21 to $19^{\circ} \mathrm{C}$ during cooling. The stability of phase change performance after at least 100 cycles described in previous work [38] did not reveal any significant changes in the phase change enthalpy or temperature intervals.

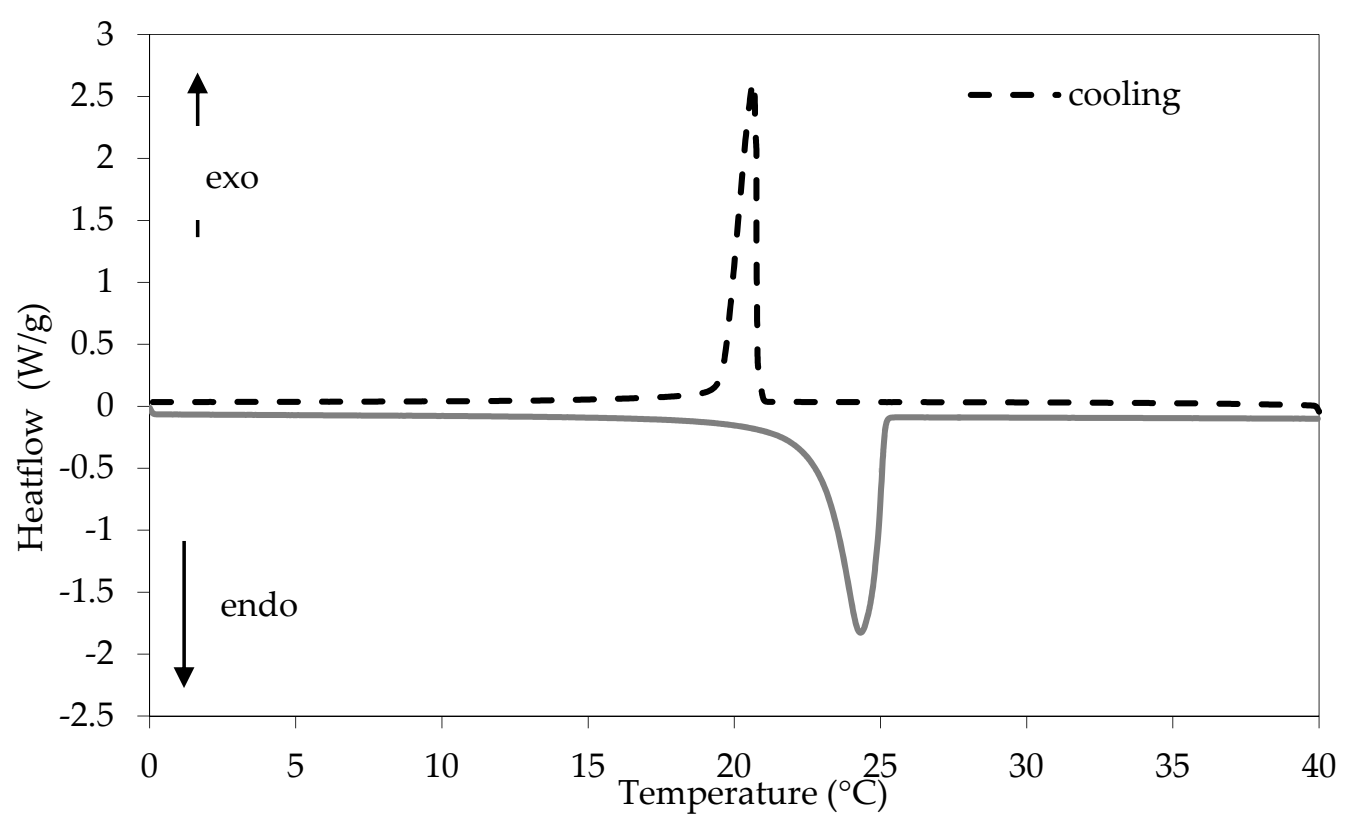

Figure 1. Phase change intervals of diatomite/dodecanol PCM composite [38].

To improve the hygroscopicity of the used plaster, an SAP admixture Hydropam composed of acrylamide/acrylic acid copolymer and sodium salt purchased from Evonic (Essen, Germany) with the ability to absorb up to $70 \mathrm{~g}$ of water per $1 \mathrm{~g}$ of material was used. The cycling behavior of SAPs was already described in the literature [40-42], and did not conclude any notable changes in material performance even after repeated swelling-deswelling cycles. The findings obtained from the performed MBV experiment from other authors also did not point to any material deterioration [36]. Based on the relevant data obtained from research works aimed at the characterization of pure SAPs, it is possible to dismiss any significant deterioration in material properties.

The reference plaster was modified in several gradual steps by means of the addition of $5 \mathrm{wt}$. \% of PCM and $1 \mathrm{wt}$. \% of SAP, up to $25 \mathrm{wt}$. \% and $5 \mathrm{wt}$. \% respectively. The application of the SAPs resulted in a minor deterioration of the fresh mixture's rheology, thus the water dosage was adjusted to achieve sufficient workability. Detailed information about the composition of the mixtures is given in Table 1. The particle size of the applied SAP and PCM admixtures was determined by a laser diffraction analyzer Bettersizer S3 Plus (Liaoning, China), and is plotted in Figure 2. 
Table 1. Plasters composition.

\begin{tabular}{ccccc}
\hline & Dry Plaster Mixture (kg) & $\mathbf{w} / \mathbf{p}$ & PCM (kg) & SAP (kg) \\
\hline RP & 10 & 0.23 & 0 & 0 \\
PSC1 & 10 & 0.24 & 0.5 & 0.1 \\
PSC2 & 10 & 0.27 & 1 & 0.2 \\
PSC3 & 10 & 0.29 & 1.5 & 0.3 \\
PSC4 & 10 & 0.32 & 2 & 0.4 \\
PSC5 & 10 & 0.35 & 2.5 & 0.5 \\
\hline
\end{tabular}

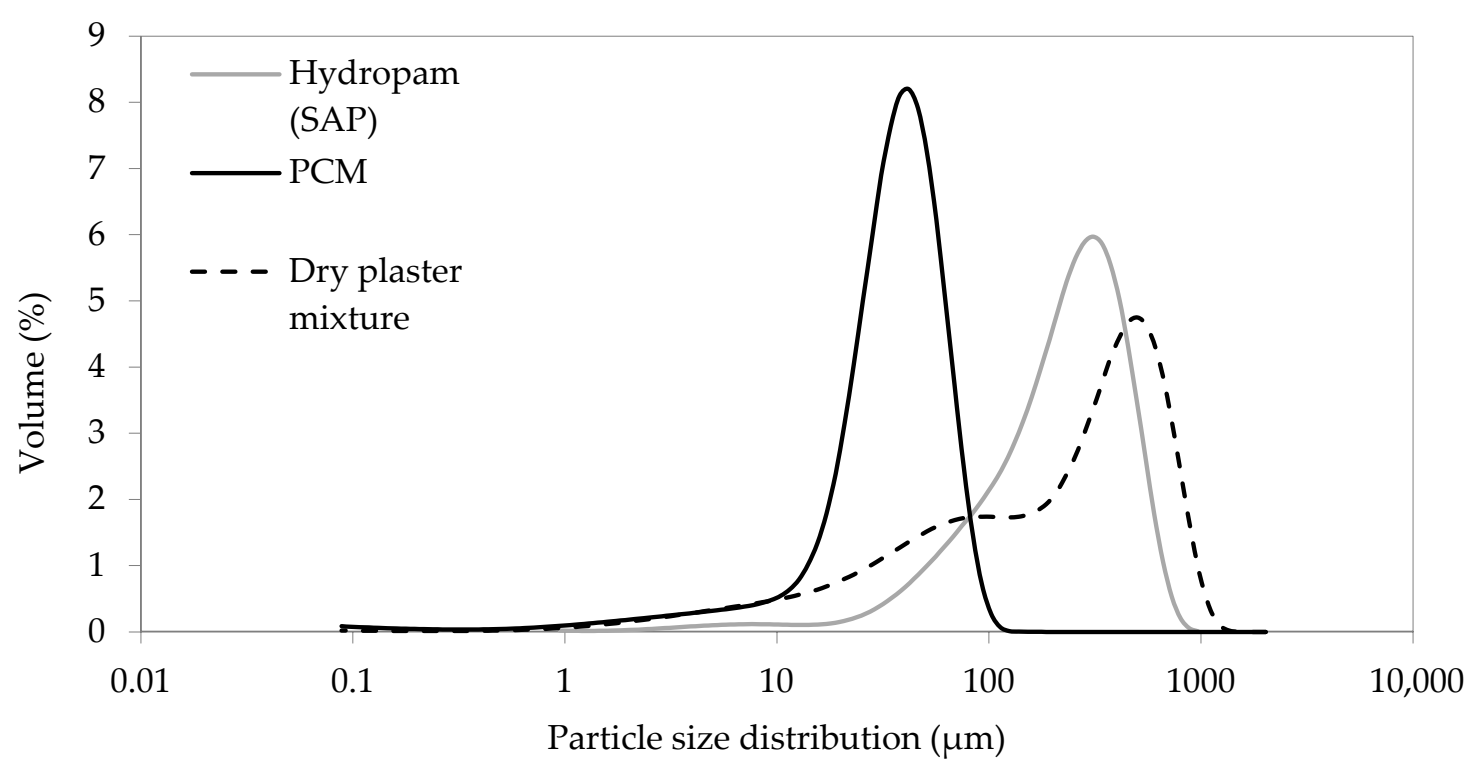

Figure 2. Particle size distribution of used PCM composite, SAP, and dry plaster mixture.

The mixture proportions of the designed mixtures of modified plasters are given in Table 2, where water/plaster ratio $(\mathrm{w} / \mathrm{p})$ describes the ratio between water and dry plaster mixture.

Table 2. Basic material properties.

\begin{tabular}{cccc}
\hline Mixture & Bulk Density $\left(\mathbf{k g} / \mathbf{m}^{\mathbf{3}}\right)$ & Matrix Density $\mathbf{( k g / \mathbf { m } ^ { \mathbf { 3 } } )}$ & Total Open Porosity $\mathbf{( \% )}$ \\
\hline RP & $1604 \pm 39$ & $2506 \pm 13$ & $35.99 \pm 1.57$ \\
PSC1 & $1516 \pm 36$ & $2492 \pm 16$ & $39.17 \pm 0.95$ \\
PSC2 & $1476 \pm 41$ & $2441 \pm 14$ & $39.53 \pm 1.23$ \\
PSC3 & $1419 \pm 23$ & $2413 \pm 12$ & $41.19 \pm 1.32$ \\
PSC4 & $1372 \pm 45$ & $2356 \pm 13$ & $41.77 \pm 1.08$ \\
PSC5 & $1362 \pm 24$ & $2311 \pm 15$ & $41.06 \pm 1.11$ \\
\hline
\end{tabular}

The prepared samples were kept in used molds for 2 days and stored in highly humid conditions $(\mathrm{RH}=95 \%)$ for 26 days after demolding. Consequently, the samples were dried at $80^{\circ} \mathrm{C}$ for $72 \mathrm{~h}$ till steady-state mass was obtained.

\subsection{Experimental Methods}

In order to access the effect of the applied PCM and SAP admixture on the microstructure of the studied plasters, the basic material properties, such as the total open porosity, bulk, and matrix density, were determined on five samples. The matrix density was obtained by the helium pycnometry Pycnomatic ATC (ThermoScientific, Waltham, MA, USA), bulk density was determined via the gravimetric principle, and so the total open porosity can be calculated from the bulk and matrix density 
values. The relative expanded uncertainty of the bulk density determination experiments was 3.1\%, and was $1.7 \%$ for matrix density.

The pore size distribution was studied with the help of Mercury Intrusion Porosimetry (MIP) Pascal 140 and Pascal 440 porosimeters (ThermoScientific, Waltham, MA, USA) with the assumption of the circular cross-section of the capillaries and a mercury contact angle of $130{ }^{\circ} \mathrm{C}$. For pore size distribution, three independent samples were measured for each mixture.

The mechanical performance of the studied plasters was assessed by a flexural strength test on $160 \mathrm{~mm} \times 40 \mathrm{~mm} \times 40 \mathrm{~mm}$ prisms (5 specimens) by using the hydraulic testing device Servoplus Evolution (Matest, Treviolo, Italy) with a stiff loading frame and with a capacity up to $6000 \mathrm{kN}$. The pull-out test was employed for the characterization of material adhesion according to EN 732577. The expanded uncertainty of flexural strength was $4.2 \%$, and was $3.7 \%$ for pull-out strength.

The determination of change temperatures and enthalpies was done by differential scanning calorimetry (DSC) analysis employing the 822e apparatus (Mettler Toledo, Greifensee, Switzerland) equipped with an FT 900 cooling device (Julabo, Seelbach, Germany). Five independent measurement procedures with an average weight of the sample of about $30 \mathrm{mg}$ were done. Samples were placed in an aluminum crucible and the following heating/cooling rates were used: $5 \mathrm{~min}$ of the isothermal regime, cooling at $0.5^{\circ} \mathrm{C} / \mathrm{min}$ from a temperature of $40^{\circ} \mathrm{C}$ to a temperature of $0{ }^{\circ} \mathrm{C} ; 5 \mathrm{~min}$ of the isothermal regime, heating at $0.5^{\circ} \mathrm{C} / \mathrm{min}$ from $0{ }^{\circ} \mathrm{C}$ to $40^{\circ} \mathrm{C} ; 5 \mathrm{~min}$ of the isothermal regime. The relative uncertainty of the onset and endset phase change temperature was $2.3 \% /{ }^{\circ} \mathrm{C}$. All the experiments were done in an air atmosphere with a flow rate of $40 \mathrm{~mL} / \mathrm{min}$. The calibration of the device was done according to ISO 11357-1. The onset and endset temperatures were achieved according to ISO 11357-3. Inaccuracies in the measurement of latent heat were corrected according to Koci et al. [43], and the relative uncertainty was $5.7 \%$.

The thermal conductivity measurement performed by the ISOMET 2114 (Applied Precision, Rača, Slovakia) was done by a surface cylindrical probe with a measuring range of $0.015 \mathrm{~W} /(\mathrm{m} \cdot \mathrm{K})$ to $0.7 \mathrm{~W} /(\mathrm{m} \cdot \mathrm{K})$ and an accuracy of $5 \% / 0.001 \mathrm{~W} /(\mathrm{m} \cdot \mathrm{K})$. The device operates on the basis of a dynamic measurement principle that enables multiple measurements thanks to a reduced measurement period.

The water sorptivity properties were obtained from the water absorption experiment. Here, the studied samples were insulated from lateral sides to maintain one-dimensional transport, hung on automatic balances connected to the datalogger, and immersed a few millimeters under the water level. The mass change was recorded, thus the water absorption coefficient is defined as

$$
A=\frac{i}{\sqrt{t}}
$$

where $i\left(\mathrm{~kg} / \mathrm{m}^{2}\right)$ is the cumulative water absorption and $t(\mathrm{~s})$ is the measurement period. Consequently, the moisture diffusivity $\kappa_{\text {app }}\left(\mathrm{m}^{2} / \mathrm{s}\right)$ was given by the following formula

$$
\kappa_{\text {app }}=\left(\frac{A}{w_{\text {sat }}-w_{0}}\right)^{2}
$$

where $w_{\text {sat }}\left(\mathrm{kg} / \mathrm{m}^{3}\right)$ is the saturated moisture content and $w_{0}\left(\mathrm{~kg} / \mathrm{m}^{3}\right)$ the moisture content of the dry sample.

The water vapor transmission properties were determined on the basis of the dry cup method arrangement. Five samples with a circular cross-section of $100 \mathrm{~mm}$ and a thickness of about $25 \mathrm{~mm}$ were used. The sealed cups were placed in a controlled climate chamber $\left(t=21^{\circ} \mathrm{C}, \mathrm{RH}=50 \%\right)$ and weighed periodically. To increase the accuracy of the measurement, combined temperature/relative humidity probes (Ahlborn, Holzkirchen, Germany) were placed in the cup for monitoring RH development. 
The achieved values of mass gain were used for the calculation of the water vapor transmission properties according to the following equation

$$
\delta=\frac{\Delta m \cdot d}{S \cdot \tau \cdot \Delta p_{p}}
$$

$\Delta m(\mathrm{~kg})$ is the change in sample mass due to water vapor gains diffused through the sample, $d(\mathrm{~m})$ is the sample thickness, $S\left(\mathrm{~m}^{2}\right)$ the specimen surface, $\tau(\mathrm{s})$ the duration of the experiment relevant to mass change, and $\Delta p_{p}(\mathrm{~Pa})$ the difference between partial water vapor pressure in the climatic chamber and in the cup with the silica gel. Afterward, the water vapor diffusion coefficient $D\left(\mathrm{~m}^{2} / \mathrm{s}\right)$ and water vapor diffusion resistance factor $\mu(-)$ were calculated by using Equations (4) and (5)

$$
\begin{gathered}
D=\frac{\delta \cdot R \cdot T}{M} \\
\mu=\frac{D_{a}}{D}
\end{gathered}
$$

$R(\mathrm{~J} /(\mathrm{K} \cdot \mathrm{mol})$ is the universal gas constant, $M(\mathrm{~kg} / \mathrm{mol})$ the molar mass of water, $T(\mathrm{~K})$ the absolute temperature, and $D_{\mathrm{a}}\left(\mathrm{m}^{2} / \mathrm{s}\right)$ the diffusion coefficient of water vapor in the air. The expanded uncertainty of the measurement was $3.3 \%$.

Sorption and desorption isotherms were obtained by using a dynamic DVS-Advantage vapor sorption device (Surface Measurement Systems, London, UK) to get mass gains/loss at 20, 40, 60, 80, and $95 \% \mathrm{RH}$. A DVS-Advantage device was operating in $\mathrm{dm} / \mathrm{dt}$ to define the equilibrium point. The $\mathrm{dm} / \mathrm{dt}$ value of $0.00004 \% / \mathrm{min}$ was applied for all replicates. Three samples of each material were measured due to the time-consuming measuring scheme. The hysteresis of the sorption isotherms was calculated from the obtained sorption and desorption curves.

The moisture buffering of the developed plasters was studied due to its contribution to the passive moderation of indoor relative humidity levels according to the approach suggested by McGregor et al. [44]. Samples with know surfaces were exposed to cyclic moisture loading at a given temperature $\left(21^{\circ} \mathrm{C}\right)$. For this purpose, a dynamic DVS-Advantage vapor sorption device was set to maintain cycles of $70 \% \mathrm{RH}$ for $16 \mathrm{~h}$ and $30 \% \mathrm{RH}$ for $8 \mathrm{~h}$. The mass gain/loss was recorded for 5 complete cycles $(=120 \mathrm{~h})$. Consequently, the moisture buffer value (MBV) was calculated as the maximum moisture uptake per $8 \mathrm{~h}$ of absorption cycle considering the selected $\mathrm{RH}$ gradient of $40 \%$. The relative uncertainty of the measurement was $4.0 \%$.

\section{Results and Discussion}

As one can see (Table 2), the obtained results point to the substantial effect of the SAP and PCM admixtures applied in terms of basic material properties. In particular, a notable decrease in bulk density was observed according to the lowered density of the applied admixtures as well as the increased water dosage. Namely, the bulk density was dropped from the initial $1604 \mathrm{~kg} / \mathrm{m}^{3}$ for reference plaster to about 20\% for the PSC 5 mixture. Taking into account the minor effect of the applied admixtures on matrix density, the total open porosity was shifted up to $41 \%$, i.e., about $15 \%$ higher compared to the reference mixture. A better understanding of the observed changes in the material structure is accessed in Figure 3 with the help of Mercury Intrusion Porosimetry. Here, the modified plasters exhibited a significant increase in the macroporous range, while the micro- and mesoporous ranges did not result in such intensive changes. A possible explanation can be found in the increased $\mathrm{w} / \mathrm{b}$ ratio that promoted the formation of larger voids. On the other hand, the application of SAP with great swelling capability can be viewed as a factor that influenced void creation. After the initial mixing period, the SAP particles absorbed a substantial amount of water which remained swollen during the formation of the solid structure. The consequent slow liberation of the water contained in the SAP particles may result in the internal curing of the mixtures, which could promote the pozzolanic reaction of the applied PCM composite. As reported, internal curing may results in the healing of 
small pores due to the hydration of unreacted particles; however, this phenomenon is more distinct for concrete mixtures [45].

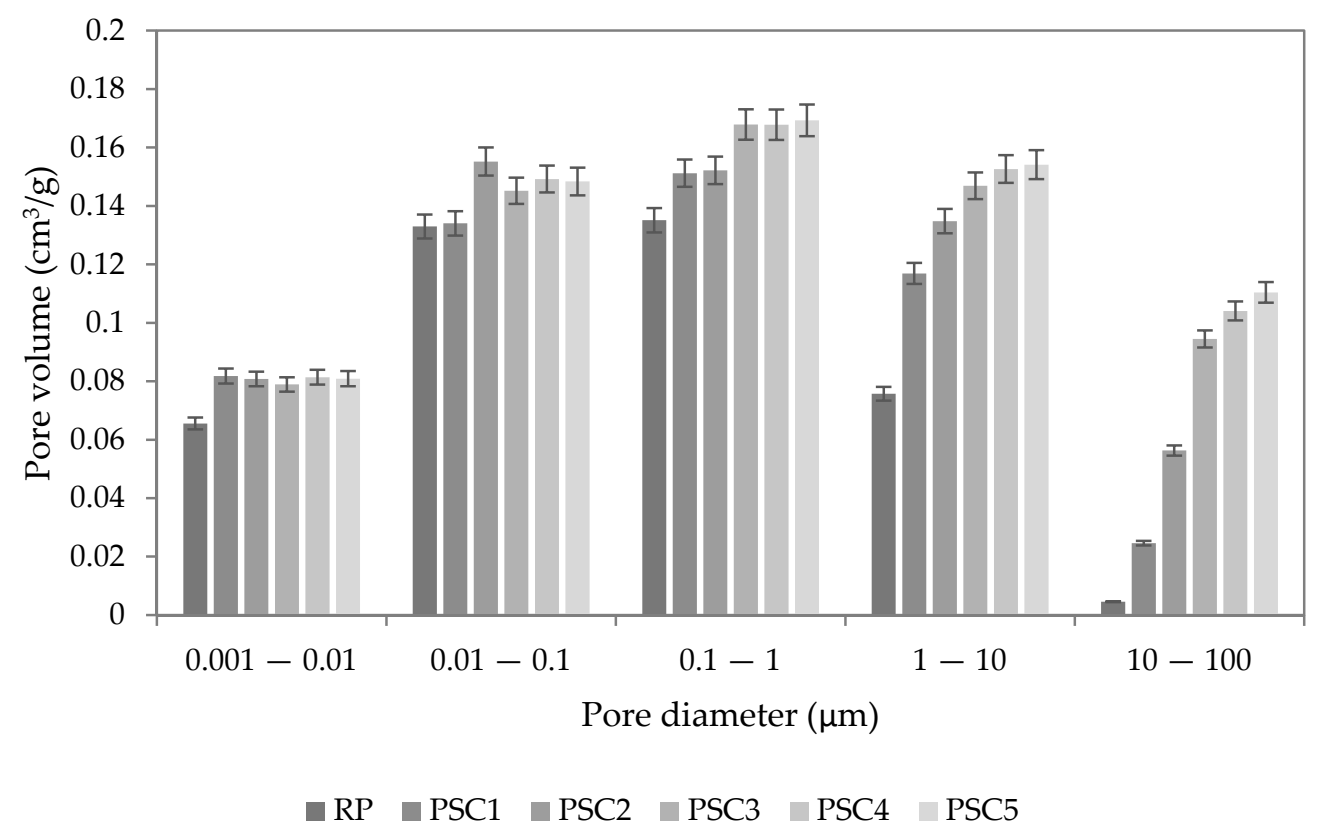

Figure 3. Pore size distribution of studied plasters.

The limited changes in the micropores' formation can be assigned to the filling of voids with very fine PCM composite particles. The described effects are more visible for mixtures with higher admixture dosages. Since the macropore volume correlates with the mechanical performance of the cementitious materials, a notable drop in flexural strength can be expected [46].

The mechanical parameters of the modified plasters are displayed in Figure 4. As revealed, a gradual decrease in flexural strength resulted in a drop from the initial $1.46 \mathrm{MPa}$ to $0.76 \mathrm{MPa}$. In other words, the applied modification has a negative effect, despite the pozzolanic activity of the diatomite-based PCM composite. This fact can be assigned predominantly to the adverse effects of the used SAPs on mechanical strength due to the particle swelling and consequent formation of larger voids. Internal curing secured by SAPs may provide some benefits; however, this phenomenon is more relevant for concrete mixture maturing since the $\mathrm{w} / \mathrm{b}$ ratio is usually substantially lowered, thus the number of unreacted cement particles remains higher. Considering the characteristics of the applied admixtures, notable contradictory effects can be observed. While the pozzolanic activity contributes to the preservation of mechanical performance, the increased $w / b$ ratio, and the shift in macroporous range due to SAP swelling, worsened the strength of the materials. Looking at the pull-out test results, only minor changes can be distinguished. This parameter of the plasters, very important for the construction practice, remained almost unchanged for almost all studied plasters without any significant deterioration. The application of the inert PCM admixture usually led to the significant deterioration of functional properties; on the other hand, the use of tailor-made admixtures with extended functionality and good compatibility with the cementitious composite does not pose a significant barrier to the building practice. In this sense, the applied SAP particles increased the adhesion, as a critical parameter for the application of plasters. Particular attention should be paid to the only limited deterioration of mechanical properties, which would limit the use of such materials in building practice since the deterioration of functional properties can be perceived as a fundamental drawback in the wider application of building materials with higher utility values. 


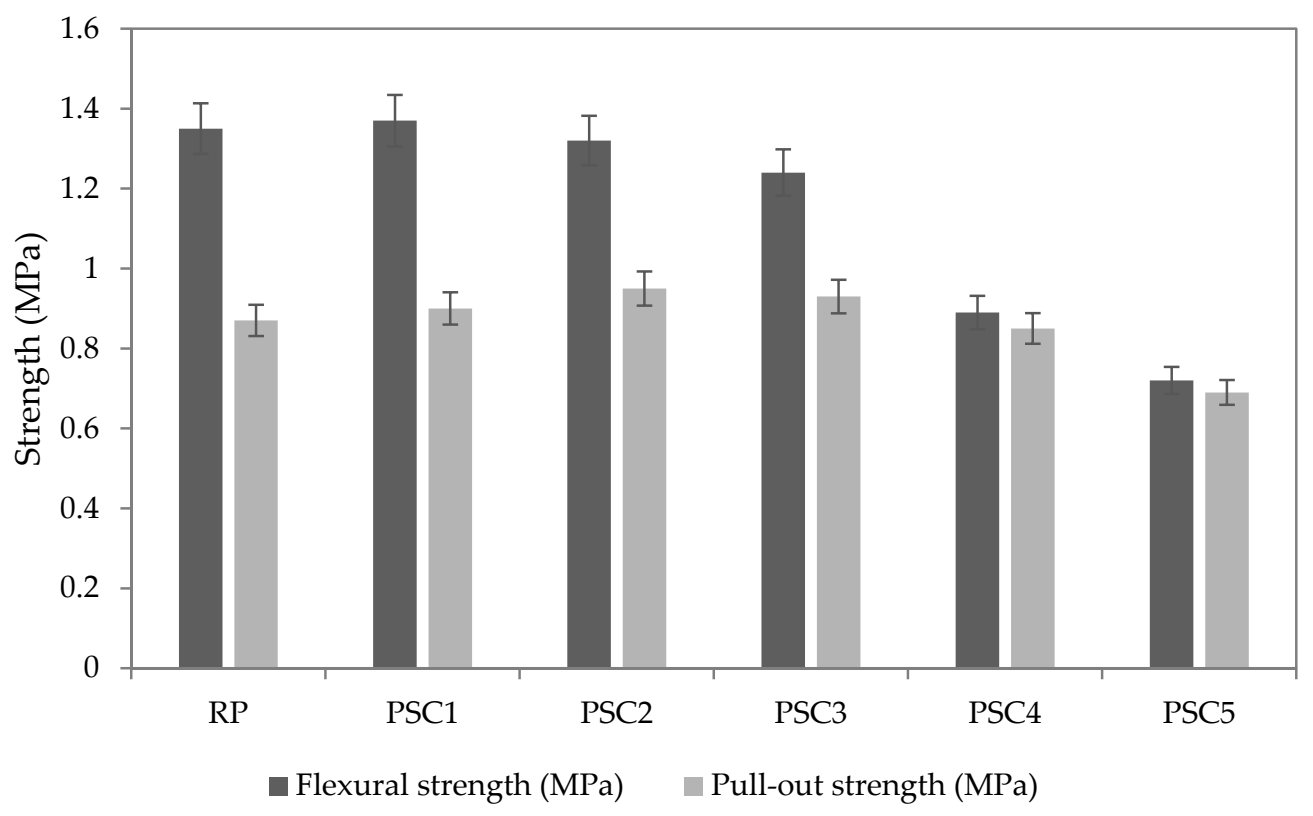

Figure 4. Mechanical performance of studied plasters.

The increased thermal storage capacity, besides the moisture moderation, poses one of the main advantages as regards a reduction in energy consumption presented in this manuscript. Detailed phase change characteristics of particular plasters are revealed in detail in Table 3 (RP did not exhibit the phase change). To be specific, the incorporation of PCM admixture did not result in any significant difference in phase change temperature compared to the original material, which remained within the desired temperature range suitable for indoor temperature moderation. As shown, the amount of latent heat (Figure 5) applicable to the utilization of the excessive heat energy/release of stored energy was increased proportionally according to the dosage of PCM admixture. Namely, the plaster PSC1 revealed the capability to release/absorb $4.23 \pm 0.24-4.53 \pm 0.26 \mathrm{~J} / \mathrm{g}$ according to the phase change cycle. The applied dosage of PCM composite corresponds with the data recorded for the pure PCM composite without any significant deterioration or any negative effect accompanying the plaster mixture preparation. The latent heat values were gradually increased up to $16.18 \pm 0.8 \mathrm{~J} / \mathrm{g} / 16.47 \pm 0.88 \mathrm{~J} / \mathrm{g}$, obtained for PSC5 plaster. As reported by other researchers, the achieved values are in the satisfactory range considering the material's application in building envelopes, as well as in the moderation of ambient thermal comfort. Compared to the work of Chen et al. [47], who utilized diatomite as the skeleton material, slightly lowered values of the latent heat of the phase change were obtained. The performed analysis did not reveal any bimodal curve during the heating or cooling cycle, as observed by Mankel et al. [48], which may decrease the thermal energy storage performance and dimmish the overall benefits that accompany the passive moderation of building interiors.

Table 3. Phase change interval and latent heat of studied plasters.

\begin{tabular}{ccccc}
\hline \multicolumn{5}{c}{ Phase Change Temperature $\left({ }^{\circ} \mathbf{C}\right)$} \\
\hline \multicolumn{2}{c}{ Heating } & \multicolumn{2}{c}{ Cooling } \\
\hline Mixture & Onset & Endset & Onset & Endset \\
\hline RP & - & - & - & - \\
PSC1 & $21.96 \pm 0.36$ & $24.78 \pm 0.43$ & $20.12 \pm 0.33$ & $18.47 \pm 0.29$ \\
PSC2 & $22.13 \pm 0.24$ & $24.89 \pm 0.38$ & $20.08 \pm 0.35$ & $18.96 \pm 0.33$ \\
PSC3 & $22.07 \pm 0.52$ & $25.14 \pm 0.61$ & $20.74 \pm 0.52$ & $19.11 \pm 0.47$ \\
PSC4 & $21.87 \pm 0.51$ & $25.01 \pm 0.59$ & $20.68 \pm 0.62$ & $19.06 \pm 0.42$ \\
PSC5 & $22.16 \pm 0.45$ & $25.43 \pm 0.50$ & $20.39 \pm 0.36$ & $19.21 \pm 0.35$ \\
\hline
\end{tabular}




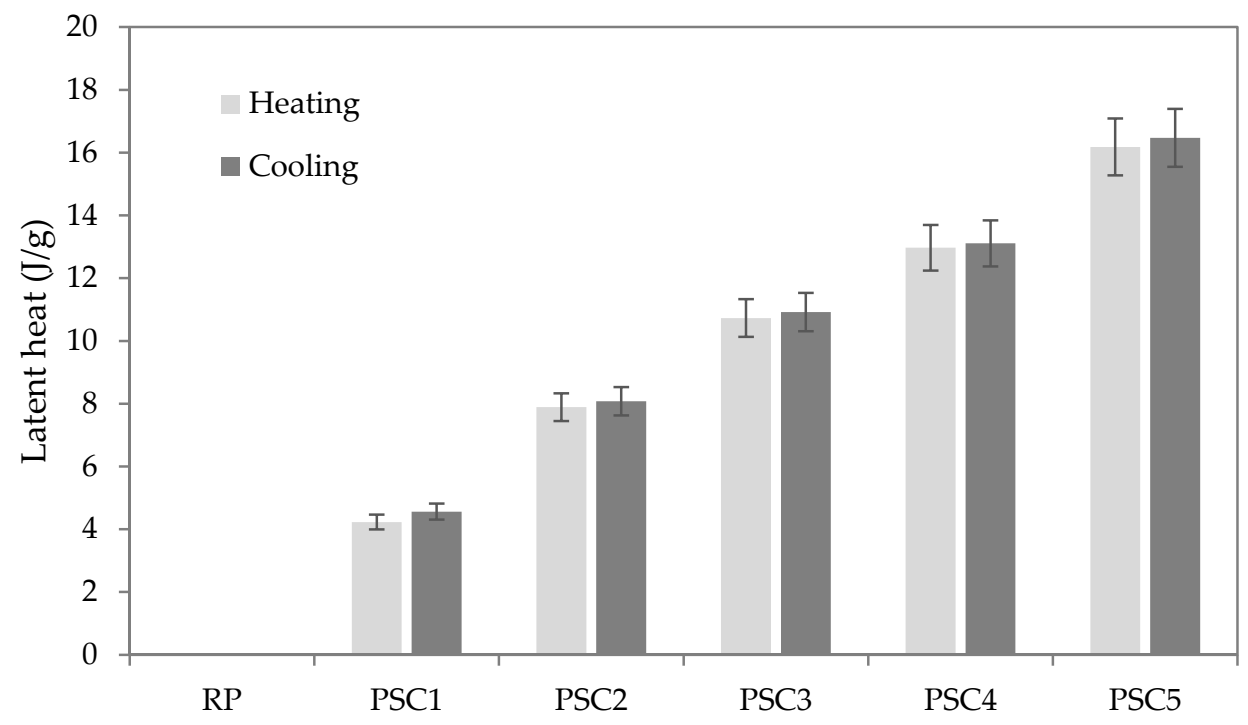

Figure 5. Obtained changes in latent heat of studied plasters during cooling/heating cycle.

As revealed in Table 4, the thermal conductivity of the studied samples exhibited very similar results in terms of both thermal conductivity and thermal diffusivity, considering the error of the measurement. While the reference plaster reached about $0.54 \mathrm{~W} /(\mathrm{mK})$, the thermal conductivity of the modified plaster was slightly decreased due to the higher porosity. To be specific, up to $0.48 \mathrm{~W} /(\mathrm{mK})$. The observed variations in thermal conductivity can be assigned also to the incorporation of the applied admixtures. In particular, SAPs in a semi-saturated state may increase the thermal conductivity. Similar findings were revealed also by other researchers, who highlighted the effect of the applied PCM medium $[15,49,50]$. The importance of low thermal conductivity cannot be viewed as the desired goal, since the limited thermal conductivity should negatively affect the phase change transition, thus permitting only partial utilization of the thermal storage performance [10].

Table 4. Thermal properties of studied plasters.

\begin{tabular}{ccc}
\hline Mixture & Thermal Conductivity $(\mathbf{W} /(\mathbf{m K}))$ & Thermal Diffusivity $\left(\mathbf{m}^{2} / \mathbf{s}\right)$ \\
\hline RP & $0.543 \pm 0.004$ & $0.365 \pm 0.003$ \\
PSC1 & $0.532 \pm 0.004$ & $0.333 \pm 0.004$ \\
PSC2 & $0.533 \pm 0.004$ & $0.351 \pm 0.002$ \\
PSC3 & $0.514 \pm 0.005$ & $0.330 \pm 0.003$ \\
PSC4 & $0.505 \pm 0.003$ & $0.324 \pm 0.003$ \\
PSC5 & $0.480 \pm 0.004$ & $0.312 \pm 0.004$ \\
\hline
\end{tabular}

The effect of the applied admixtures and various dosages of SAP, in particular, was experimentally studied to reveal the moisture moderation potential. In this sense, the results from the free water uptake experiment based on five independent measurements are given in Table 5. As one can see, the initial values of the absorption coefficient, as well as moisture diffusivity, are similar to those of ordinary plasters as reported by Colinart et al. [51] and Pavlík et al. [52]. On the other hand, the incorporation of the applied SAP and PCM admixtures substantially increased the moisture uptake properties. Since the effect of only PCM diatomite composite was studied in Refs. [53,54] with only minor modulation of hygric properties, the application of SAPs induced more significant changes. Taking into account results from the research aimed at the utilization of only the diatomite-based PCM or SAP [15,38], the concurrent application of both admixtures creates a synergistic effect that significantly changes the moisture properties despite the relatively low volume of used SAP. Specifically, the water absorption coefficient was almost tripled compared to the reference plaster. The obtained increase in the total open porosity contributed to the shift in the moisture transport properties; however, this does not 
correspond to such changes as were revealed. The achieved parameters refer to the increased sorptivity of the modified plasters, which themselves refer not only to the passive moderation of interior climate but also to their possible utilization as remediation plaster.

Table 5. Hygric properties of studied plasters.

\begin{tabular}{|c|c|c|}
\hline Mixture & Water Absorption Coefficient $\left(\mathrm{kg} / \mathrm{m}^{2} \mathrm{~s}^{1 / 2}\right)$ & Moisture Diffusivity $\left(\mathrm{m}^{2} / \mathrm{s}\right)$ \\
\hline $\mathrm{RP}$ & $0.112 \pm 0.011$ & $1.61 \times 10^{-8} \pm 0.078 \times 10^{-8}$ \\
\hline PSC1 & $0.136 \pm 0.009$ & $3.02 \times 10^{-8} \pm 0.09 \times 10^{-8}$ \\
\hline PSC2 & $0.176 \pm 0.012$ & $8.46 \times 10^{-8} \pm 0.17 \times 10^{-8}$ \\
\hline PSC3 & $0.226 \pm 0.014$ & $2.63 \times 10^{-7} \pm 0.07 \times 10^{-7}$ \\
\hline PSC4 & $0.254 \pm 0.024$ & $4.90 \times 10^{-7} \pm 0.16 \times 10^{-7}$ \\
\hline PSC5 & $0.294 \pm 0.023$ & $7.95 \times 10^{-7} \pm 0.21 \times 10^{-7}$ \\
\hline
\end{tabular}

The water vapor transmission capability of the modified plasters is given in Table 6. Here, only minor changes compared to the reference plaster were obtained. In particular, the water vapor resistance factor was decreased from 9.3 to 7.9 , and a similar effect can be observed also for the water vapor diffusivity. Such results are driven mainly by the increased total open porosity of the studied plasters. Contrary to the investigation of Park et al. [35], who used a modified gypsum board, the obtained values of water vapor resistance were significantly lower. The work of Shi et al. [55] focused also on the modification of the gypsum board by microencapsulated PCM, and they achieved a roughly doubled water vapor resistance factor.

Table 6. Water vapor diffusion properties of studied plasters.

\begin{tabular}{ccc}
\hline Mixture & Water Vapor Resistance Factor $(-)$ & Water Vapor Diffusivity $\left(\mathbf{m}^{\mathbf{2}} / \mathbf{s}\right)$ \\
\hline RP & $9.31 \pm 0.60$ & $2.66 \times 10^{-6} \pm 0.14 \times 10^{-6}$ \\
PSC1 & $8.63 \pm 0.31$ & $2.87 \times 10^{-6} \pm 0.10 \times 10^{-6}$ \\
PSC2 & $8.36 \pm 0.34$ & $2.98 \times 10^{-6} \pm 0.12 \times 10^{-6}$ \\
PSC3 & $8.22 \pm 0.41$ & $3.01 \times 10^{-6} \pm 0.15 \times 10^{-6}$ \\
PSC4 & $8.30 \pm 0.44$ & $2.98 \times 10^{-6} \pm 0.14 \times 10^{-6}$ \\
PSC5 & $7.92 \pm 0.29$ & $3.13 \times 10^{-6} \pm 0.11 \times 10^{-6}$ \\
\hline
\end{tabular}

The provided comparison of these results shows that the studied lime-cement plasters are relatively easily penetrated by water vapor, which can therefore be released and bound according to the current conditions in the building interiors. On top of that, too high a water vapor resistance factor may create an impermeable surface layer that cannot respond to fluctuations in the interior relative humidity levels.

The ability of plasters to absorb water vapor is shown by the sorption isotherms accessed by the DVS-Advantage device in Figure 6. Looking at the results, a noticeable increase in the moisture equilibrium content was reached. While the reference plaster attained about $4.3 \%$ of gravimetric water content, PSC5 reached up to $11.2 \%$, and thus the water content was almost tripled. A further increase in relative humidity resulted in a more pronounced mass increase in all the modified plasters. 

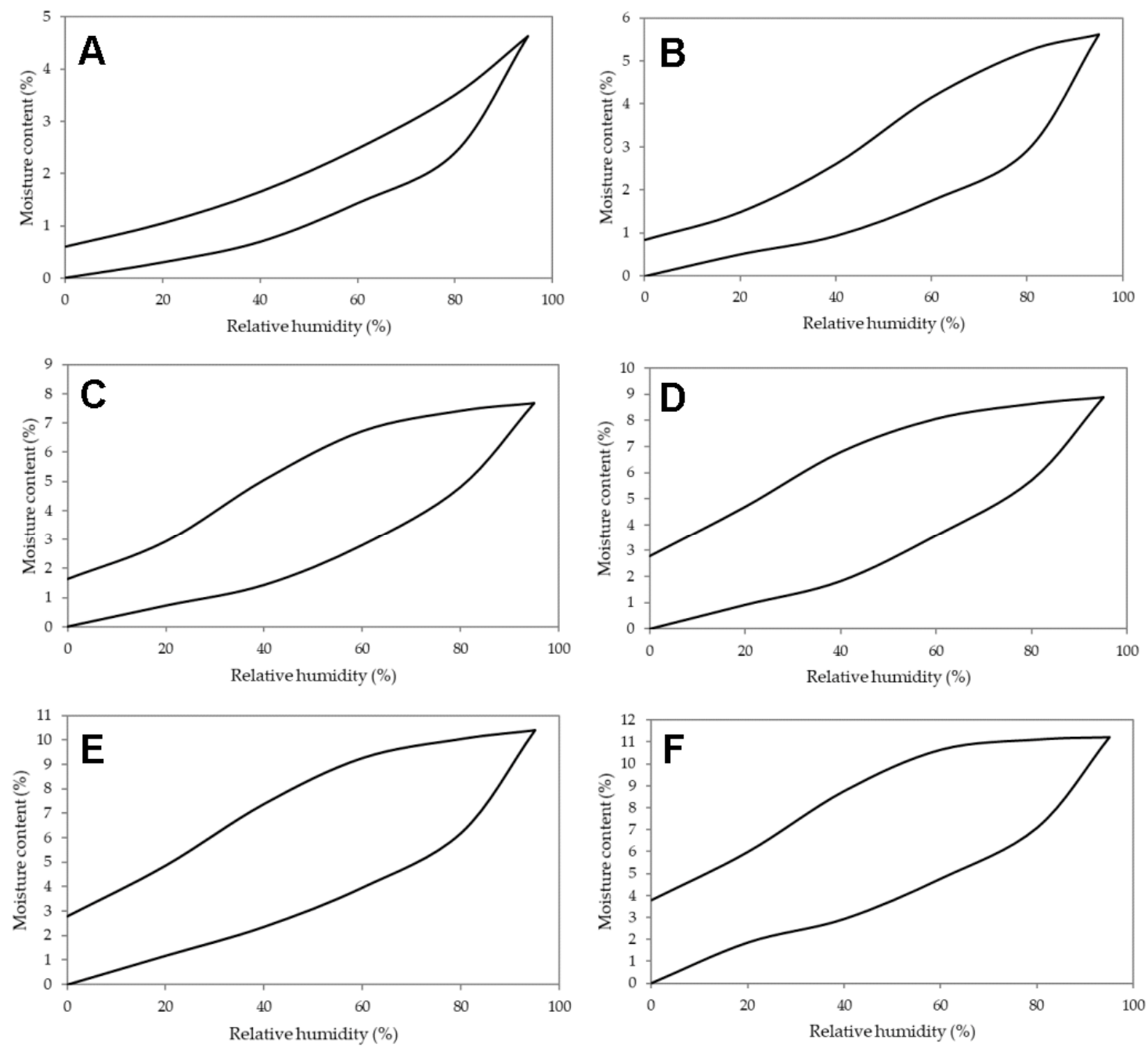

Figure 6. Sorption and desorption isotherms: (A) RP; (B) PSC1; (C) PSC2; (D) PSC3; (E) PSC4; (F) PSC5.

The criterion of highly saturated moisture content for indoor humidity control was confirmed by Chen et al. [47]. Notable changes were observed in the hysteresis range, which was increased in line with the increased content of applied admixtures. This phenomenon corresponds mainly to the used SAP dosages, since the incorporation of PCMs based on diatomite did not reveal such intensive modifications [56]. The revealed changes rather refer to the potential of SAPs to modify the air humidity $[37,57]$ to a greater extent, and can be compared with the favorable results of the hemp shiv introduced by Mazhoud et al. [5], who prepared hemp-lime plaster with improved moisture buffering.

Particular attention should be paid to the understanding of changes in sorption/desorption hysteresis. As shown in Figure 7, the hysteresis between the sorption and desorption cycle is more evident for mixtures with a higher content of SAPs. This finding may be driven by the increased water retention capacity of SAPs and consequent modifications in water vapor sorption capacity. On the other hand, the hygric performance of the modified materials still represents a substantial improvement that can find prospective utilization in the passive moderation of indoor relative humidity. Despite the importance of the water vapor hysteresis for moisture buffering, this effect was not described in detail in the similar works of Yang et al. [57] or Vieira et al. [58], despite its crucial impact on plasters' functionalization. As reported by Hou et al. [59], the water vapor hysteresis needs to be taken into account within the assessment of moisture-buffering materials. 


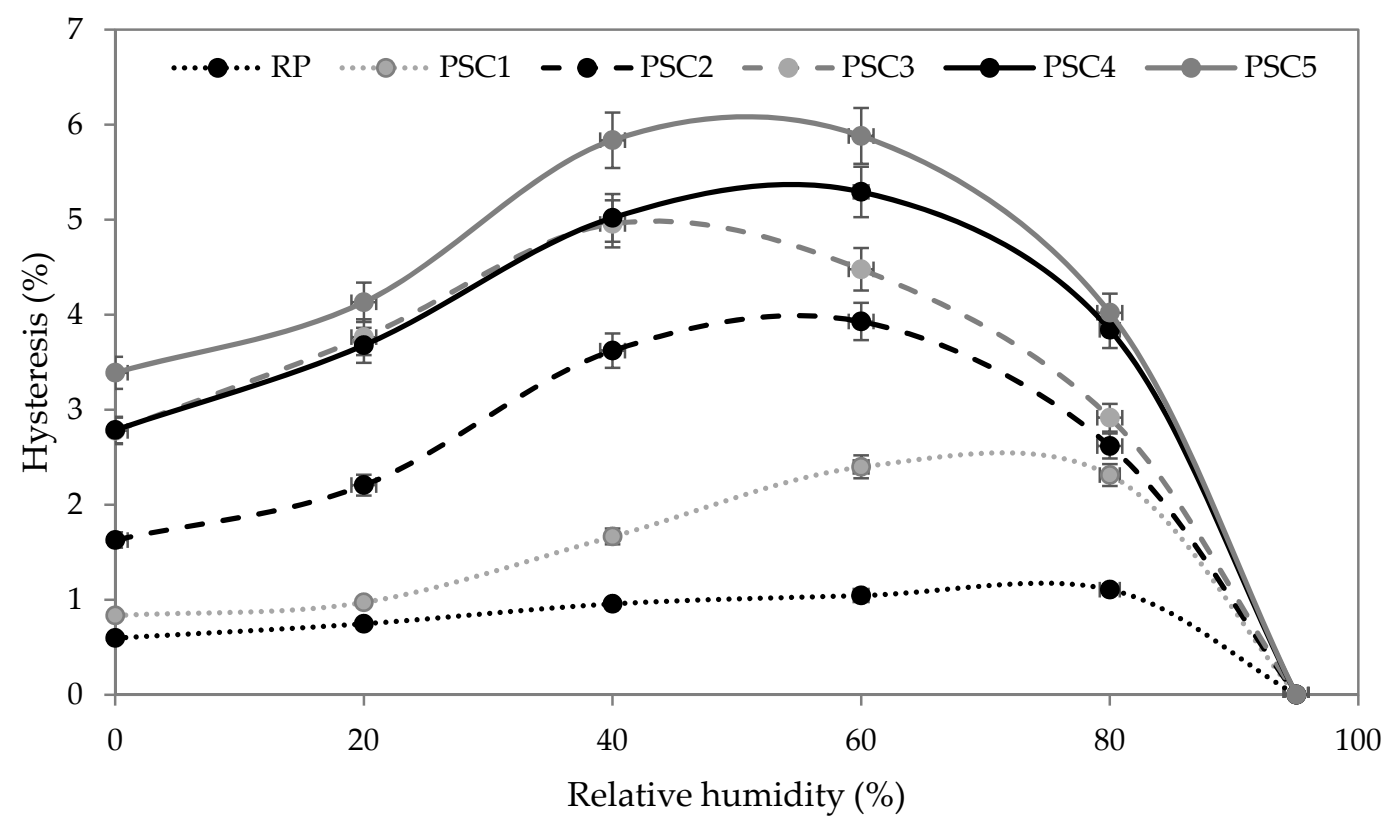

Figure 7. Water vapor hysteresis of studied plasters at 20, 40, 60, 80 and 95\% RH.

The MBV values given in Figure 8 closely correlate with the moisture storage capacity, and only a minor relation with moisture transmission properties can be noted. Suppositionally, the synergic effect of both the applied admixtures shifted the moisture buffering of the designed plasters up to $1.62 \mathrm{~g} /\left(\% \mathrm{RHm}^{2}\right)$ from an initial $0.89 \mathrm{~g} /\left(\% \mathrm{RHm}{ }^{2}\right)$. Even more favorable results can be expected in the case of increased temperature, since this may result in the acceleration of the water vapor transmission and a lower retention capacity of the used SAPs. The effect of the applied diatomite-based PCM is rather minor, due to the partial saturation of the diatomite porous space with dodecanol (PCM medium) and the only limited effectivity compared to SAPs [53]. This notwithstanding, the obtained values of MBV are significantly higher compared to the utilization of vermiculite or other traditionally used lightweight aggregates [44].

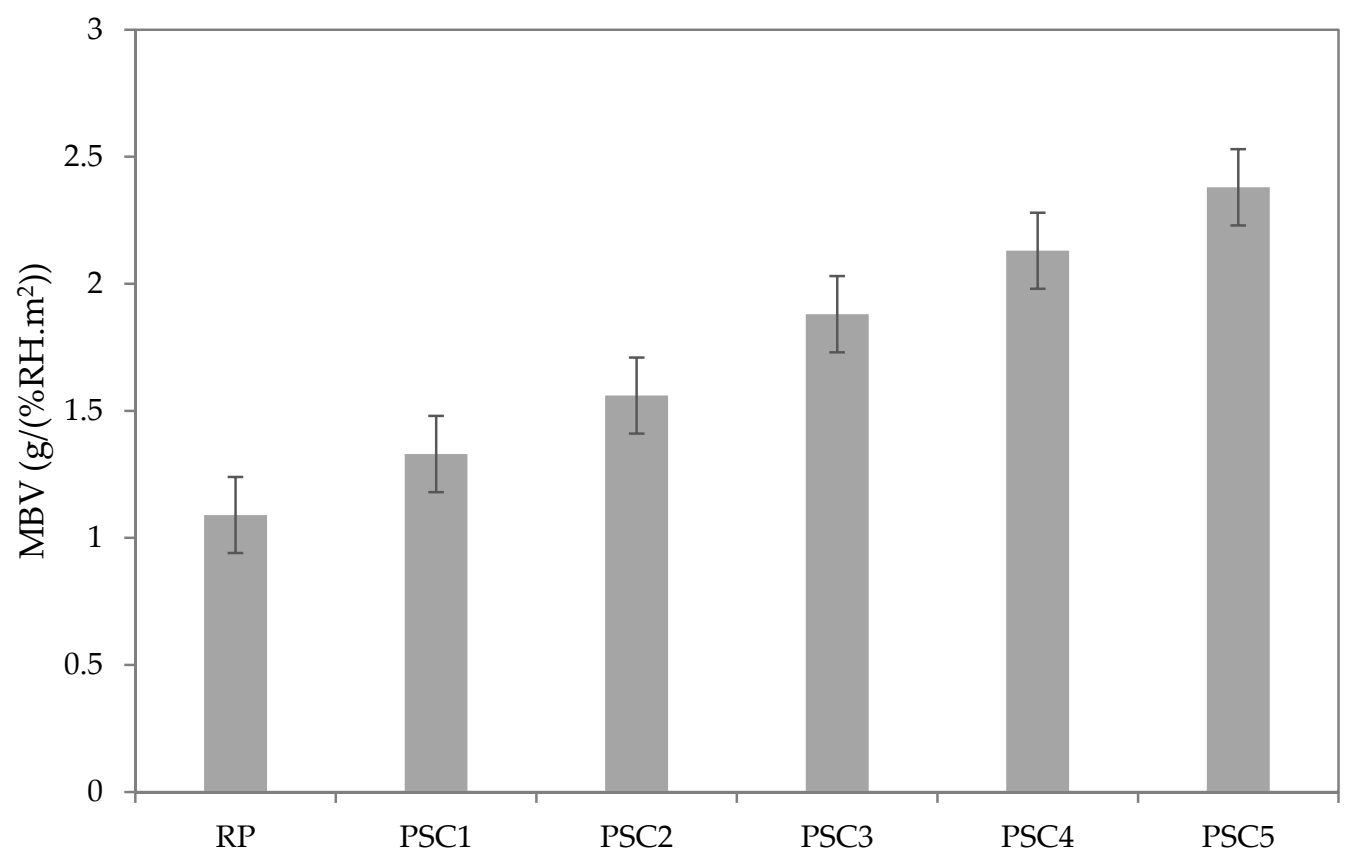

Figure 8. Comparison of moisture-buffering values of studied plasters. 


\section{Conclusions}

In this study, the laboratory-prepared form-stable PCM composites based on diatomite and dodecanol together with Hydropam SAP were used as admixtures for the preparation of a novel plaster with enhanced performance in terms of a passive hygrothermal moderation of indoor air. The performed experimental characterization of the material parameters of the plasters with up to $25 \mathrm{wt}$. \% of PCM and $5 \mathrm{wt}$. \% revealed significant changes in the functional performance, thus the synergistic effect can be assigned to the application of SAP and PCM. The most important findings can be described as follows:

- Application of selected admixtures influenced the basic material properties to a minor extent, namely, a slight increase in the total open porosity should be noted;

- The incorporation of the diatomite-based PCM composite into plaster did not affect the phase change transition in terms of the temperature range. The phase change enthalpy was increased proportionally to the applied dosage;

- Modifications in the hygric properties, and sorption characteristics in particular, point to the beneficial effect of the highly hygroscopic SAP admixture. In fact, the water vapor storage capability was tripled, although the hysteresis was shifted substantially;

- The humidity control performance accessed by MBV increased up to $2.38 \mathrm{~g} /\left(\% \mathrm{RHm}{ }^{2}\right)$, which corresponds to excellent moisture buffering, according to Nordtest classification, thanks to the synergic effect of both applied admixtures;

- The obtained results show the energy-saving potential of the developed phase change, humidity control plaster due to extended functionality.

Consequent research should be aimed at the long-term performance of modified plasters, together with semi- or real-scale experiments that allow the calculation of potential energy savings.

Author Contributions: Conceptualization, J.F. and J.K.; methodology, J.F., J.K. and L.P.; validation, J.F., J.K. and M.K.; formal analysis, R.Č.; investigation, J.F., L.P., J.P. and J.K.; resources, J.F., R.Č. and M.K.; data curation, J.F., J.K. and J.P.; writing—original draft preparation, J.F. and J.K.; writing—review and editing, J.F.; visualization, J.F.; supervision, R.Č.; project administration, J.F.; funding acquisition, J.F. All authors have read and agreed to the published version of the manuscript.

Funding: This research was funded by the Czech Science Foundation, under project No. 18-03997S and by specific university research by the Institute of Technology and Business in České Budějovice, under project No. SVV201802.

Conflicts of Interest: The authors declare no conflict of interest.

\section{References}

1. Park, J.Y.; Wilson, E.; Parker, A.; Nagy, Z. The good, the bad, and the ugly: Data-driven load profile discord identification in a large building portfolio. Energy Build. 2020, 215, 19. [CrossRef]

2. Asdrubali, F.; Ballarini, I.; Corrado, V.; Evangelisti, L.; Grazieschi, G.; Guattari, C. Energy and environmental payback times for an NZEB retrofit. Build. Environ. 2019, 147, 461-472. [CrossRef]

3. Brambilla, A.; Salvalai, G.; Imperadori, M.; Sesana, M.M. Nearly zero energy building renovation: From energy efficiency to environmental efficiency, a pilot case study. Energy Build. 2018, 166, 271-283. [CrossRef]

4. Koci, J.; Koci, V.; Madera, J. Uncertainty in Moisture Transport Modelling and its Effect on Ice Formation in Porous Building Materials. In Proceedings of the Thermophysics 2018, Terchova, Slovakia, 7-9 November 2018; Trnik, A., Matiasovsky, P., Medved, I., Eds.; 2018; Volume 1988.

5. Mazhoud, B.; Collet, F.; Pretot, S.; Chamoin, J. Hygric and thermal properties of hemp-lime plasters. Build. Environ. 2016, 96, 206-216. [CrossRef]

6. Pavlik, Z.; Fort, J.; Pavlikova, M.; Pokorny, J.; Trnik, A.; Cerny, R. Modified lime-cement plasters with enhanced thermal and hygric storage capacity for moderation of interior climate. Energy Build. 2016, 126, 113-127. [CrossRef]

7. Lee, H.; Ozaki, A.; Lee, M.; Yamamoto, T. Humidity control effect of vapor-permeable walls employing hygroscopic insulation material. Indoor Air 2020, 30, 346-360. [CrossRef] 
8. Johra, H.; Heiselberg, P.; Le Dreau, J. Influence of envelope, structural thermal mass and indoor content on the building heating energy flexibility. Energy Build. 2019, 183, 325-339. [CrossRef]

9. Alam, M.; Singh, H.; Suresh, S.; Redpath, D.A.G. Energy and economic analysis of Vacuum Insulation Panels (VIPs) used in non-domestic buildings. Appl. Energy 2017, 188, 1-8. [CrossRef]

10. Rathore, P.K.S.; Shukla, S.K.; Gupta, N.K. Potential of microencapsulated PCM for energy savings in buildings: A critical review. Sustain. Cities Soc. 2020, 53, 21.

11. Mofijur, M.; Mahlia, T.M.I.; Silitonga, A.S.; Ong, H.C.; Silakhori, M.; Hasan, M.H.; Putra, N.; Rahman, S.M.A. Phase Change Materials (PCM) for Solar Energy Usages and Storage: An Overview. Energies 2019, 12, 3167. [CrossRef]

12. Navarro, L.; Sole, A.; Martin, M.; Barreneche, C.; Olivieri, L.; Tenorio, J.A.; Cabeza, L.F. Benchmarking of useful phase change materials for a building application. Energy Build. 2019, 182, 45-50. [CrossRef]

13. Urgessa, G.; Yun, K.K.; Yeon, J.; Yeon, J.H. Thermal responses of concrete slabs containing microencapsulated low-transition temperature phase change materials exposed to realistic climate conditions. Cem. Concr. Compos. 2019, 104, 8. [CrossRef]

14. Essid, N.; Loulizi, A.; Neji, J. Compressive strength and hygric properties of concretes incorporating microencapsulated phase change material. Constr. Build. Mater. 2019, 222, 254-262. [CrossRef]

15. Fort, J.; Novotny, R.; Trnik, A.; Cerny, R. Preparation and Characterization of Novel Plaster with Improved Thermal Energy Storage Performance. Energies 2019, 12, 3318. [CrossRef]

16. Jiang, L.; Liu, Z.M.; Yuan, Y.; Wang, Y.J.; Lei, J.X.; Zhou, C.L. Fabrication and characterization of fatty acid/wood-flour composites as novel form-stable phase change materials for thermal energy storage. Energy Build. 2018, 171, 88-99.

17. Tao, Y.B.; He, Y.L. A review of phase change material and performance enhancement method for latent heat storage system. Renew. Sustain. Energy Rev. 2018, 93, 245-259. [CrossRef]

18. Stritih, U.; Tyagi, V.V.; Stropnik, R.; Paksoy, H.; Haghighat, F.; Joybari, M.M. Integration of passive PCM technologies for net-zero energy buildings. Sustain. Cities Soc. 2018, 41, 286-295. [CrossRef]

19. Fateh, A.; Borelli, D.; Weinlader, H.; Devia, F. Cardinal orientation and melting temperature effects for PCM-enhanced light-walls in different climates. Sustain. Cities Soc. 2019, 51, 19. [CrossRef]

20. Li, Z.X.; Al-Rashed, A.; Rostamzadeh, M.; Kalbasi, R.; Shahsavar, A.; Afrand, M. Heat transfer reduction in buildings by embedding phase change material in multi-layer walls: Effects of repositioning, thermophysical properties and thickness of PCM. Energy Convers. Manag. 2019, 195, 43-56. [CrossRef]

21. Koci, J.; Fort, J.; Cerny, R. Energy efficiency of latent heat storage systems in residential buildings: Coupled effects of wall assembly and climatic conditions. Renew. Sustain. Energy Rev. 2020, 132, 12. [CrossRef]

22. Orlik-Kozdon, B.; Steidl, T. Experimental and analytical determination of water vapour transmission properties of recyclable insulation material. Constr. Build. Mater. 2018, 192, 798-807. [CrossRef]

23. Kumaran, M.K.; Lackey, J.C.; Normandin, N.; Tariku, F.; van Reenen, D. Heat, air, and moisture transport properties of several North American bricks and mortar mixes. J. Test. Eval. 2004, 32, 383-389. [CrossRef]

24. Brzyski, P.; Suchorab, Z. Capillary Uptake Monitoring in Lime-Hemp-Perlite Composite Using the Time Domain Reflectometry Sensing Technique for Moisture Detection in Building Composites. Materials 2020, 13, 1677. [CrossRef] [PubMed]

25. Ivanic, A.; Kravanja, G.; Kidess, W.; Rudolf, R.; Lubej, S. The Influences of Moisture on the Mechanical, Morphological and Thermogravimetric Properties of Mineral Wool Made from Basalt Glass Fibers. Materials 2020, 13, 2392. [CrossRef]

26. Bajno, D.; Bednarz, L.; Matkowski, Z.; Raszczuk, K. Monitoring of Thermal and Moisture Processes in Various Types of External Historical Walls. Materials 2020, 13, 505. [CrossRef]

27. Jiang, Y.H.; Phelipot-Mardele, A.; Collet, F.; Lanos, C.; Lemke, M.; Ansell, M.; Hussain, A.; Lawrence, M. Moisture buffer, fire resistance and insulation potential of novel bio-clay plaster. Constr. Build. Mater. 2020, 244, 10. [CrossRef]

28. Nizovtsev, M.I.; Letushko, V.N.; Borodulin, V.Y.; Sterlyagov, A.N. Experimental studies of the thermo and humidity state of a new building facade insulation system based on panels with ventilated channels. Energy Build. 2020, 206, 12. [CrossRef]

29. Esty, B.; Permaul, P.; DeLoreto, K.; Baxi, S.N.; Phipatanakul, W. Asthma and Allergies in the School Environment. Clin. Rev. Allergy Immunol. 2019, 57, 415-426. [CrossRef] 
30. Nakayama, Y.; Nakaoka, H.; Suzuki, N.; Tsumura, K.; Hanazato, M.; Todaka, E.; Mori, C. Prevalence and risk factors of pre-sick building syndrome: Characteristics of indoor environmental and individual factors. Environ. Health Prev. Med. 2019, 24, 10. [CrossRef]

31. Kreiger, B.K.; Srubar, W.V. Moisture buffering in buildings: A review of experimental and numerical methods. Energy Build. 2019, 202, 17. [CrossRef]

32. McGregor, F.; Fabbri, A.; Ferreira, J.; Simoes, T.; Faria, P.; Morel, J.C. Procedure to determine the impact of the surface film resistance on the hygric properties of composite clay/fibre plasters. Mater. Struct. 2017, 50, 13. [CrossRef]

33. Goncalves, H.; Goncalves, B.; Silva, L.; Raupp-Pereira, F.; Senff, L.; Labrincha, J.A. Development of porogene-containing mortars for levelling the indoor ambient moisture. Ceram. Int. 2014, 40, 15489-15495. [CrossRef]

34. Buratti, C.; Belloni, E.; Merli, F. Water vapour permeability of innovative building materials from different waste. Mater. Lett. 2020, 265, 4. [CrossRef]

35. Park, J.H.; Kang, Y.J.; Lee, J.; Wi, S.; Chang, J.D.; Kim, S. Analysis of walls of functional gypsum board added with porous material and phase change material to improve hygrothermal performance. Energy Build. 2019, 183, 803-816. [CrossRef]

36. Senff, L.; Ascensao, G.; Hotza, D.; Ferreira, V.M.; Labrincha, J.A. Assessment of the single and combined effect of superabsorbent particles and porogenic agents in nanotitania-containing mortars. Energy Build. 2016, 127, 980-990. [CrossRef]

37. Fort, J.; Sal, J.; Koci, J.; Cerny, R. Energy Efficiency of Novel Interior Surface Layer with Improved Thermal Characteristics and Its Effect on Hygrothermal Performance of Contemporary Building Envelopes. Energies 2020, 13, 2012. [CrossRef]

38. Fort, J.; Trnik, A.; Pavlikova, M.; Pavlik, Z.; Cerny, R. Fabrication of Dodecanol/Diatomite Shape-Stabilized PCM and Its Utilization in Interior Plaster. Int. J. Thermophys. 2018, 39, 11. [CrossRef]

39. Fort, J.; Koci, J.; Pokorny, J.; Cerny, R. Influence of Superabsorbent Polymers on Moisture Control in Building Interiors. Energies 2020, 13, 2009. [CrossRef]

40. Patra, S.K.; Swain, S.K. Swelling Study of Superabsorbent PAA-co-PAM/Clay Nanohydrogel. J. Appl. Polym. Sci. 2011, 120, 1533-1538. [CrossRef]

41. Li, A.; Wang, A.Q.; Chen, J.M. Studies on poly(acrylic acid)/attapulgite superabsorbent composite. I. Synthesis and characterization. J. Appl. Polym. Sci. 2004, 92, 1596-1603. [CrossRef]

42. Qi, X.H.; Liu, M.Z.; Chen, Z.B.; Liang, R. Preparation and properties of diatomite composite superabsorbent. Polym. Adv. Technol. 2007, 18, 184-193. [CrossRef]

43. Koci, V.; Fort, J.; Madera, J.; Scheinherrova, L.; Trnik, A.; Cerny, R. Correction of Errors in DSC Measurements Using Detailed Modeling of Thermal Phenomena in Calorimeter-Sample System. IEEE Trans. Instrum. Meas. 2020, 69, 8178-8186.40. [CrossRef]

44. McGregor, F.; Heath, A.; Shea, A.; Lawrence, M. The moisture buffering capacity of unfired clay masonry. Build. Environ. 2014, 82, 599-607. [CrossRef]

45. Mignon, A.; Graulus, G.J.; Snoeck, D.; Martins, J.; De Belie, N.; Dubruel, P.; Van Vlierberghe, S. pH-sensitive superabsorbent polymers: A potential candidate material for self-healing concrete. J. Mater. Sci. 2015, 50, 970-979. [CrossRef]

46. He, Z.M.; Shen, A.Q.; Guo, Y.C.; Lyu, Z.H.; Li, D.S.; Qin, X.; Zhao, M.; Wang, Z.L. Cement-based materials modified with superabsorbent polymers: A review. Constr. Build. Mater. 2019, 225, 569-590. [CrossRef]

47. Chen, Z.; Qin, M.H. Preparation and hygrothermal properties of composite phase change humidity control materials. Appl. Therm. Eng. 2016, 98, 1150-1157. [CrossRef]

48. Mankel, C.; Caggiano, A.; Konig, A.; Schicchi, D.S.; Sam, M.N.; Koenders, E. Modelling the Thermal Energy Storage of Cementitious Mortars Made with PCM-Recycled Brick Aggregates. Materials 2020, 13, 1064. [CrossRef]

49. Thongtha, A.; Khongthon, A.; Boonsri, T.; Chan, H.Y. Thermal Effectiveness Enhancement of Autoclaved Aerated Concrete Wall with PCM-Contained Conical Holes to Reduce the Cooling Load. Materials 2019, 12, 2170. [CrossRef]

50. Sari, A.; Bicer, A.; Karaipekli, A.; Al-Sulaiman, F.A. Preparation, characterization and thermal regulation performance of cement based-composite phase change material. Sol. Energy Mater. Sol. Cells 2018, 174, 523-529. [CrossRef] 
51. Colinart, T.; Vinceslas, T.; Lenormand, H.; De Menibus, A.H.; Hamard, E.; Lecompte, T. Hygrothermal properties of light-earth building materials. J. Build. Eng. 2020, 29, 10. [CrossRef]

52. Pavlik, Z.; Jerman, M.; Fort, J.; Cerny, R. Monitoring Thermal Performance of Hollow Bricks with Different Cavity Fillers in Difference Climate Conditions. Int. J. Thermophys. 2015, 36, 557-568. [CrossRef]

53. Wan, H.; Sun, Z.W.; Huang, G.S.; Xu, X.H.; Yu, J.H. Calculation of the maximum moisture buffering thickness of building wall layer of hygroscopic material. Build. Environ. 2019, 160, 11. [CrossRef]

54. Wu, Z.M.; Qin, M.H.; Zhang, M.J. Phase change change humidity control material and its impact on building energy consumption. Energy Build. 2018, 174, 254-261. [CrossRef]

55. Shi, C.N.; Zhang, H.B.; Xuan, Y.L. Experimental investigation of thermal properties and moisture buffering performance of composite interior finishing materials under different airflow conditions. Build. Environ. 2019, 160, 10. [CrossRef]

56. Senff, L.; Modolo, R.C.E.; Ascensao, G.; Hotza, D.; Ferreira, V.M.; Labrincha, J.A. Development of mortars containing superabsorbent polymer. Constr. Build. Mater. 2015, 95, 575-584. [CrossRef]

57. Yang, H.L.; Peng, Z.Q.; Zhou, Y.; Zhao, F.; Zhang, J.; Cao, X.Y.; Hu, Z.W. Preparation and performances of a novel intelligent humidity control composite material. Energy Build. 2011, 43, 386-392. [CrossRef]

58. Vieira, J.; Senff, L.; Goncalves, H.; Silva, L.; Ferreira, V.M.; Labrincha, J.A. Functionalization of mortars for controlling the indoor ambient of buildings. Energy Build. 2014, 70, 224-236. [CrossRef]

59. Hou, P.M.; Qin, M.H.; Cui, S.Q.; Zu, K. Preparation and characterization of metal-organic framework/microencapsulated phase change material composites for indoor hygrothermal control. J. Build. Eng. 2020, 31, 11. [CrossRef]

Publisher's Note: MDPI stays neutral with regard to jurisdictional claims in published maps and institutional affiliations. 